\title{
Association of Schizoid and Schizotypal Personality disorder with violent crimes and homicides in Greek prisons
}

\author{
Athanasios Apostolopoulos ${ }^{*}$, loannis Michopoulos ${ }^{1}$, loannis Zachos ${ }^{3}$, Emmanouil Rizos ${ }^{1}$, Georgios Tzeferakos ${ }^{1}$, \\ Vasiliki Manthou ${ }^{3}$, Charalambos Papageorgiou ${ }^{2}$ and Athanasios Douzenis ${ }^{1}$
}

\begin{abstract}
Background: Personality disorders (PDs) have been associated with both violent crimes and homicides in many studies. The proportion of PDs among prisoners reaches up to $80 \%$. For male prisoners, the most common PD in the literature is antisocial PD. The aim of this study was to investigate the association between PDs and violent crimes/ homicides of male prisoners in Greece.

Methods: A sample of 308 subjects was randomly selected from a population of 1300 male prisoners incarcerated in two Greek prisons, one urban and one rural. The presence of PDs was assessed using the Mini International Neuropsychiatric Interview (MINI) and the Personality Diagnostic Questionnaire-4 (PDQ-4). Using logistic regression models PD types and PD "Clusters" (independent variables) were associated with "violent/non-violent crimes" and "homicides/non homicides" (dependent variables).

Results: "Cluster A"PDs (Paranoid, Schizoid, and Schizotypal) were diagnosed in 16.2\%, "Cluster B" (Antisocial, Borderline, Histrionic, Narcissistic) in 66.9\% and "Cluster C" (Obsessive-Compulsive, Dependent, Avoidant) in 2.9\% of the studied population. Violent crimes and homicides were found significantly associated with "Cluster A" PDs ( $p=0.022$, $p=0.020$ ). The odds ratio of committing violent crimes was 2.86 times higher for patients with "Cluster A" PDs than the ones without PDs. In addition, the odds ratio of committing homicides was 4.25 times higher for patients with "Cluster $A^{\prime \prime}$ PDs. In separate analyses, the commitment of violent crimes as well as homicides, was significantly associated with Schizoid $(p=0.043, p=0.020)$ and Schizotypal PD $(p=0.017, p=0.030)$.

Conclusions: The majority of prisoners was found to suffer from a PD, mainly the Antisocial "Cluster B", but the commitment of violent crimes and homicides was significantly associated only with "Cluster A" PDs and specifically with Schizoid and Schizotypal PD.
\end{abstract}

Keywords: Personality disorders, Prisoners, Cluster A, Schizotypal, Schizoid

\section{Background}

According to DSM-IV, the proportion of Personality Disorder (PD) types in the general population is: $5.7 \%$ for "Cluster A" (Paranoid, Schizoid, Schizotypal), 1.5\% for "Cluster B" (Antisocial, Borderline, Histrionic, Narcissistic) and 6.0\% for "Cluster C" (Obsessive-Compulsive,

\footnotetext{
*Correspondence: th.apostolopoulos@gmail.com

${ }^{1}$ 2nd Psychiatric Department of the University of Athens, Attikon Hospital, Athens, Greece

Full list of author information is available at the end of the article
}

Dependent, Avoidant) [1]. Furthermore, in $9.1 \%$ of the cases, two or more PDs co-exist [1]. Fourteen studies examined the risk of antisocial and violent behavior in 10,007 individuals with PDs, compared with over 12 million general population controls [2]. The results showed a substantially increased risk of violent outcomes in all PD types. Meta-analysis revealed that Antisocial PD and male gender were associated with the higher risks [2].

"Cluster B" PDs are affecting behavior and lifestyle and cause significant problems not only to the disordered individual but to society as well [3]. Among criminal 
offenders the proportion of Personality disorders is much higher [4] and can reach up to $80 \%$ in some studies [5]. Antisocial PD predominates among male offenders, while Borderline PD among female ones [6-8].

In a study by Riesco et al. [9] conducted in Spanish prisons, 91\% of the prisoners had one or more PDs. Antisocial PD was diagnosed in $79 \%$ of the population while Paranoid PD and Borderline PD in 52\% and 41\%, respectively. Using the Mini International Neuropsychiatric Interview (MINI) and the Personality Diagnostic Questionnaire 4 (PDQ-4), Piselli et al. [10] found that the most frequent psychiatric disorder-in incarcerated offenders-was PD (51.9\%). In a similar study by Coolidge et al. [11], $61 \%$ of prisoners had been diagnosed at least with one PD. Furthermore, Köhler et al. [12] found that the proportion of "Cluster B" PDs among incarcerated offenders was more than $62 \%$. As mentioned before, Antisocial PD is found predominantly among male prisoners. This finding is supported by several studies: Kugu et al. reported a percentage of $48.6 \%$ [13], Naidoo and Mkize 46.1\% [14] and Longato-Stadler et al. 56\% [15]. In a systematic review of Fazel and Danesh [7] - 23,000 incarcerated individuals with more than 9000 violent prisoners included-PDs were diagnosed in $42 \%$ of the sample, among which 21\% was Antisocial PD. Among prisoners in Greece, Fotiadou et al. found that the percentage of Antisocial PD was 37.5\% [16].

However, Antisocial PD is not the only PD related to violent crimes. According to Fountoulakis et al. [17], Paranoid, Antisocial, Narcissistic, Borderline and Schizoid PDs ("Clusters A and B") are all associated with violent crime. A significant association has been described, as well, between PDs of "Clusters A and B" and homicides. In case of homicide the most frequently encountered psychiatric diagnoses are PDs, drug addiction and alcohol abuse. More specifically, "Cluster B" PDs can be found in up to $60 \%$ of the cases. According to Crump et al. [18], people suffering from PDs and substance use disorders were more frequently convicted for homicide crimes. Richard-Devantoy et al. [8] claim, as well, that the association between comorbid Antisocial PD and alcoholism with murder is strong: Antisocial PD increased the risk of committing homicide 10 times compared to a Psychotic Disorder. In Finland, at least one diagnosis of PD was involved in 358 of the 593 homicides recorded from 1996 to 2004 [19].

As depicted, there is a much higher frequency of PDs in the prisons' population compared to the general population. These disorders are predominantly "Cluster B" (especially Antisocial PD), followed by "Cluster A" PDs. Despite the fact that in the recent years there seems to be an increased scientific interest in studying and understanding the link between PDs and typology of criminal behavior, there are many contradictory findings that need clarification. In Greece, there have been no studies addressing these questions in prisoners.

This study was an attempt to record PDs among male prisoners in Greece and investigate the possible association between these disorders and violent offences and homicides.

\section{Method}

\section{Study design and population}

This is a cross-sectional study conducted in two Greek prisons; one urban (Korydallos) and one rural (Domokos). Data were collected from March 2012 till August 2013. The sample comprised of 308 male individuals randomly sampled from a total of 1300 prisoners, aged between 18 and 77 years. The sample included Greek and foreign prisoners who either had the Greek citizenship or could read and speak in Greek. Every third name of the registry of the prison was chosen. In 88 cases of unavailability/difficulties in understanding the language or denial (57 cases), the next prisoner was asked to participate in the study.

Inmates who were found to be suffering from psychotic disorders during the interviews were excluded from the study.

\section{Data collection}

The psychiatric screening of prisoners was conducted with the Greek version 5.0.0 DSM-IV of Mini International Neuropsychiatric Interview (MINI) $[20,21]$ and the Greek version of Personality Diagnostic Questionnaire-4 (PDQ-4) $[4,22,23]$. The psychiatric examination was conducted by two psychiatrists. Initially demographics and other characteristics presented in Table 1 were recorded followed by a psychiatric assessment. The whole duration of the first interview was about $60 \mathrm{~min}$. During the second interview, the PDQ-4 questionnaire was administered by the examiners, who were present till the end of the test (total duration about $60 \mathrm{~min}$ ). Inmates who initially had shown mixed disorders or were not adequately assessed, were re-questioned (as suggested by the Personality Questionnaire manual) in order to conclude at one type of Personality Disorder. The third diagnostic interview's duration was about $45 \mathrm{~min}$.

Regarding the criminal record of the individuals assessed, the total number of incarcerations as well as their index offence that led to their imprisonment at the time of the study, were recorded. The assessing psychiatrists had no knowledge of the index offence during the initial interview. The offences that led to imprisonment were divided and categorized, according to the Greek Penal Code into violent (crimes against life, personal injuries, crimes against personal freedom, crimes against 


Table 1 Demographics and other characteristics
of prisoners in Greece $(n=308)$

\begin{tabular}{|c|c|}
\hline & $N(\%)$ \\
\hline Age ( $M$, SD years) & $38.3(10.8)$ \\
\hline \multicolumn{2}{|l|}{ Nationality } \\
\hline Greek & $270(87.7)$ \\
\hline Other & $38(12.3)$ \\
\hline \multicolumn{2}{|l|}{ Educational status } \\
\hline Primary school & $162(52.6)$ \\
\hline Middle school & $125(40.6)$ \\
\hline College & $10(3.2)$ \\
\hline University & $11(3.6)$ \\
\hline \multicolumn{2}{|l|}{ Family status } \\
\hline Married & $93(30.4)$ \\
\hline Single & $160(52.3)$ \\
\hline Widowed & $6(2.0)$ \\
\hline Divorced & $39(12.7)$ \\
\hline Separated & $8(2.6)$ \\
\hline Children & $123(39.9)$ \\
\hline Violence between parents & $152(49.4)$ \\
\hline \multicolumn{2}{|l|}{ Relationship with father } \\
\hline Good & $192(62.3)$ \\
\hline Bad & $63(20.5)$ \\
\hline Casual & $53(17.2)$ \\
\hline \multicolumn{2}{|l|}{ Relationship with mother } \\
\hline Good & $245(80.1)$ \\
\hline Bad & $14(4.6)$ \\
\hline Casual & $47(15.4)$ \\
\hline Tobacco use & $295(95.8)$ \\
\hline Alcohol use & $272(88.3)$ \\
\hline Cannabis use & $208(67.5)$ \\
\hline Drug use & $179(58.5)$ \\
\hline Pyromania during childhood/puberty & $204(66.2)$ \\
\hline Gang member & $151(49.0)$ \\
\hline Animal abuse & $201(65.3)$ \\
\hline Psycho traumatic event & $126(41.0)$ \\
\hline \multicolumn{2}{|l|}{ Living status prior to imprisonment } \\
\hline Alone & $78(25.4)$ \\
\hline With family & $98(31.9)$ \\
\hline With parents & $65(21.2)$ \\
\hline Other & $66(21.5)$ \\
\hline \multicolumn{2}{|l|}{ Soldiering } \\
\hline Fulfilled & $201(65.3)$ \\
\hline Dispensation & $107(34.7)$ \\
\hline First imprisonment & $158(51.3)$ \\
\hline \multicolumn{2}{|l|}{ Type of crime } \\
\hline Violent & $95(30.8)$ \\
\hline Non-violent & $213(69.2)$ \\
\hline
\end{tabular}

$M$ mean value, $S D$ standard deviation sexuality freedom, common danger crimes) and nonviolent (crimes against ownership, debts to state, crimes related to drugs, crimes against property rights, crimes against honor, crimes related to marriage, crimes related to service, crimes related to currency). The crimes of homicide/attempted homicide were recorded separately from the other violent crimes and regardless the number of victims. Also for individuals that had multiple convictions, their most serious crime was recorded for the purpose of this study; e.g. for a conviction for both attempted murder and robbery, the individual was recorded under the category of "attempted murder".

\section{Statistical analyses}

Quantitative variables were expressed as mean values $(M)$ and standard deviations (SD), while qualitative variables were expressed as absolute frequencies $(N)$ and relative frequencies (\%). For the comparison of proportions, Chi square and Fisher's exact tests were used. Multiple logistic regression models with a stepwise method ( $p$ for entry $0.05, p$ for removal 0.10 ) were used in order to test whether PD types and PD "Clusters" were independently associated with violent crimes and homicides. PD types and PD "Clusters" were used as independent variables, whereas "violent/non-violent crimes" and "homicidesattempted homicides/non homicides" as dependent variables. Variables that regarded social, economic, demographic or clinical characteristics were not included in the analysis due to sample size. More statistical tests could have led to a lower study power. Adjusted odds ratios (OR) and the respective 95\% confidence intervals (CI) were computed. Statistical significance was set at $p \leq 0.05$. All reported $p$ values are two-tailed and analyses were conducted using SPSS statistical software (version 19.0).

\section{Results}

The study population consisted of 308 participants from a total of 1300 prisoners. Their mean age was 38.3 years $(\mathrm{SD}=10.8)$. Almost half of the participants $(51.3 \%)$ were imprisoned for the first time. For $30.8 \%$ of the participants conviction was a result of a violent crime. Homicide was recorded for 38 of the cases (12.3\%). Homicides along with attempted homicides were recorded for 46 cases (14.9\%). Demographics and other characteristics are presented in Table 1.

PDs were diagnosed in $89 \%(N=275)$ of the population. The types of PDs diagnosed are shown in Fig. 1. The most common PD was Antisocial (42.5\%), followed by Borderline (15.9\%), Narcissistic (7.8\%), Schizoid (7.1\%) and 
Paranoid (7.1\%). For $10.7 \%(N=33)$ of the participants no PD was diagnosed. "Cluster A" PDs were found in $16.2 \%$ of the participants, while "Clusters B and C" were found in $66.9 \%$ and $2.9 \%$ of the participants, respectively.

As extracted from Table 2, among prisoners with Antisocial, Borderline and Narcissistic Disorder, 77.1\%, 65.3\% and 58.3\%, respectively, had been imprisoned for nonviolent crimes. Nevertheless, most of the violent crimes $(N=30)$ as well as homicides/attempted homicides $(N=12)$ had been committed by individuals with Antisocial Disorder. Of those cases with Schizoid, Schizotypal and Paranoid disorder, 50.0\%, 66.7\% and 45.5\%, respectively, had been incarcerated for violent crimes. On the other hand, $24.2 \%$ of violent crimes were committed by inmates with no diagnosis of a PD. Subjects of "Cluster A" PDs, in total, had committed 17 of the 46 homicides/ attempted homicides.

Compared with prisoners without PD, the percentages of violent crimes and homicides/attempted homicides were significantly higher in those belonging to "Cluster $A$ " and in those with Schizoid or Schizotypal PD alone (Table 2).

Multiple logistic regression analysis with "violent crimes/no violent crimes" as the dependent variable showed that the likelihood to commit a violence crime was significantly higher in "Cluster A" PDs $(p=0.022$, $\mathrm{OR}=2.86$ ). When all the PD types were included in the model instead of PDs "Clusters", it was found that Schizoid $(p=0.043, \mathrm{OR}=3.49)$ and Schizotypal $(p=0.017, \mathrm{OR}=10.5)$ PDs were significantly associated with a higher likelihood of violence crimes. Multiple logistic regression analysis with "homicides-attempted homicides/no homicides", as dependent variable, had similar results. Prisoners of "Cluster A" $(p=0.020$, $\mathrm{OR}=4.25)$ and those with Schizoid $(p=0.020$, OR $=5.26)$ or Schizotypal $(p=0.030, \mathrm{OR}=8.80)$ PDs had significantly increased likelihood for committing or attempting a homicide (Table 3).

\section{Discussion}

\section{Personality disorders}

The assessment of PDs, based on the DSM-IV classification and structured diagnostic instruments, is conflicting. It is possible individuals who meet the criteria for a particular Personality disorder meet as well the criteria for other Personality disorders. The new diagnostic approach in DSM-5 describes the Personality disorders as qualitatively distinct clinical syndromes. Nevertheless, in this study, diagnoses were based on MINI Interview and PDQ-4 Questionnaire because the use of the same instruments with other similar studies makes the results comparable and helps the scientific discussion on the association between violent crimes and psychiatric disorders.

PDs were diagnosed in the vast majority $(89 \%)$ of the prisoners' sample. The most common PD was Antisocial

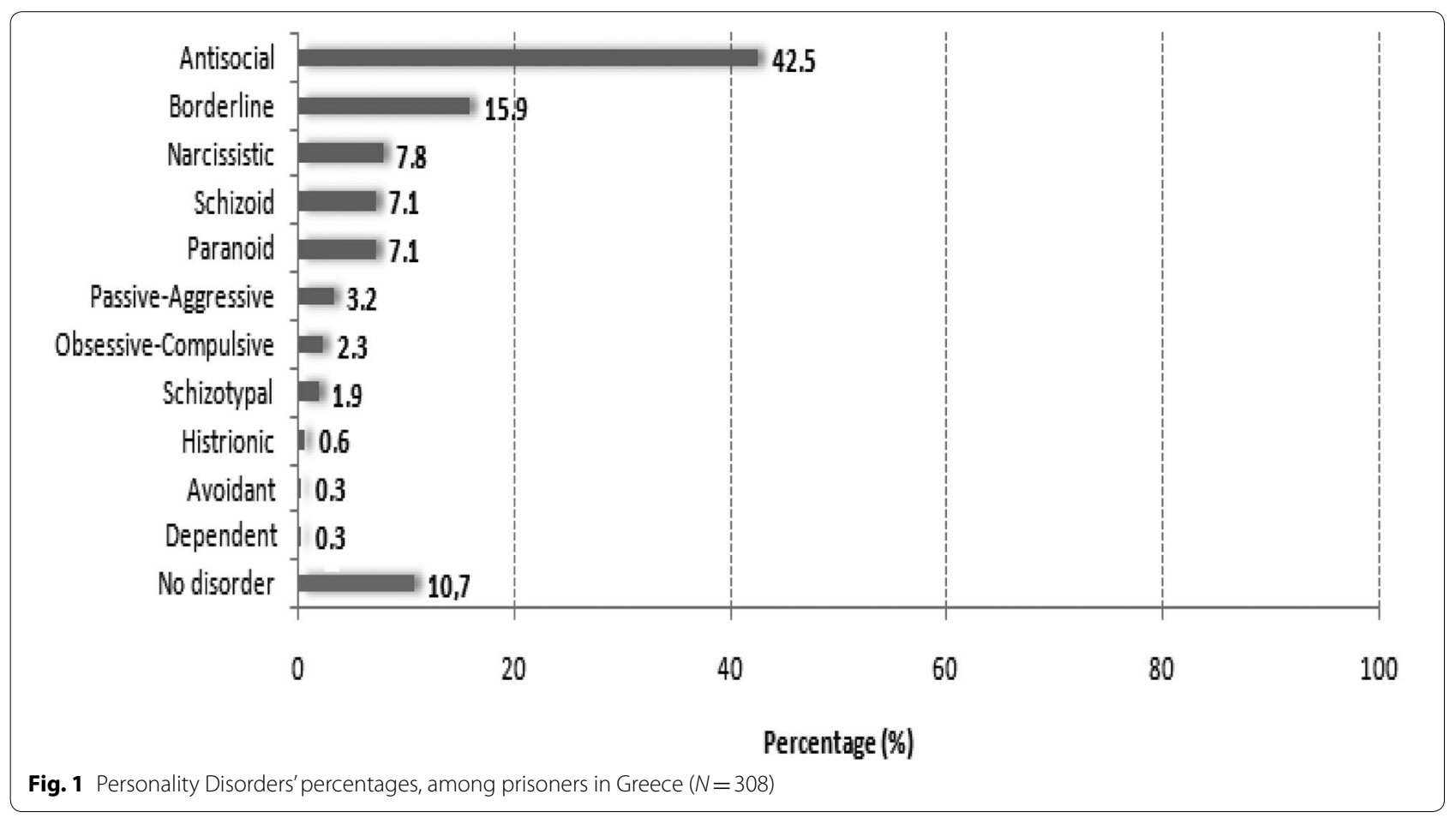


Table 2 Differences in Personality disorder percentages among prisoners in Greece with violent crimes and homicidesattempted homicides $(N=308)$

\begin{tabular}{|c|c|c|c|c|}
\hline & Violent crimes & $p^{*}$ & $\begin{array}{l}\text { Homicides/attempted } \\
\text { homicides }\end{array}$ & $p^{*}$ \\
\hline & $N(\%)$ & & $N(\%)$ & \\
\hline \multicolumn{5}{|l|}{ PD diagnosis } \\
\hline Antisocial & $30(22.9)$ & 0.870 & $12(9.2)$ & 0.608 \\
\hline Borderline & $17(34.7)$ & 0.313 & $10(20.4)$ & 0.328 \\
\hline Narcissistic & $10(41.7)$ & 0.162 & $1(4.2)$ & $0.385^{* *}$ \\
\hline Paranoid & $10(45.5)$ & 0.100 & $6(27.3)$ & $0.175^{* *}$ \\
\hline Histrionic & $1(50.0)$ & $0.454^{* *}$ & $0(0.0)$ & $1.000^{* *}$ \\
\hline Schizoid & $11(50.0)$ & 0.049 & $8(36.4)$ & $0.047^{* *}$ \\
\hline Schizotypal & $4(66.7)$ & $0.050^{* *}$ & $3(50.0)$ & $0.026^{* *}$ \\
\hline Obsessive-Compulsive & $0(0.0)$ & $0.309^{* *}$ & $0(0.0)$ & $1.000^{* *}$ \\
\hline Dependent & $0(0.0)$ & $1.000^{* *}$ & $0(0.0)$ & $1.000^{* *}$ \\
\hline Avoidant & $0(0.0)$ & $1.000^{* *}$ & $0(0.0)$ & $1.000^{* *}$ \\
\hline Passive-aggressive & $4(40.0)$ & 0.330 & $2(20.0)$ & $0.611^{* *}$ \\
\hline No PD & $8(24.2)$ & & $4(12.1)$ & \\
\hline \multicolumn{5}{|l|}{ PD Cluster } \\
\hline A & $25(50.0)$ & 0.019 & $17(34.0)$ & 0.025 \\
\hline B & $58(28.2)$ & 0.641 & $23(11.2)$ & $0.774^{* *}$ \\
\hline C & $0(0.0)$ & 0.168 & $0(0.0)$ & $0.561^{* *}$ \\
\hline
\end{tabular}

PD Personal Disorder, Cluster A PD Paranoid/Schizoid/Schizotypal PD, Cluster B PD Antisocial/Borderline/Histrionic/Narcissistic PD, Cluster C PD Obsessive/Compulsive/ Dependent/Avoidant PD

* Chi square test for the comparison with those without PD, ** Fisher's exact test

(42.5\%). The likelihood of committing a violent crime or homicide-attempt homicide,was significantly greater among those with Schizoid or Schizotypal PD.

The high prevalence of psychopathology in the population of incarcerated offenders is well documented in the literature and also reflected in this study. PDs were the most common disorders among prison inmates in Italy [10]. At least one type of PD was diagnosed in $61 \%$ of a prison population sample according to Coolidge et al. [11]. Langeveld and Melhus reported that PDs were found in $80 \%$ of the prisoners. In the same study, antisocial PD was present in more than $60 \%$ of the study population [24]. Results from a systematic review of 62 studies with a total sample of 23,000 prisoners reported that $65 \%$ of the population had PDs, and $47 \%$ had Antisocial PD [7]. Similar results were reported in Greek populations by Fountoulakis et al. [17] and Fotiadou et al. [16].

In this study Antisocial PD was diagnosed in $42.5 \%$ of the participants, Borderline PD in $15.9 \%$ and Narcissistic PD in $7.8 \%$. Histrionic PD was diagnosed only in $0.6 \%$ of the individuals. A definite dominance of "Cluster B" PDs was obvious which is in concordance with the literature. Köhler et al. found that the prevalence of "Cluster B" PDs in a sample of male incarcerated juvenile offenders in Germany was up to $62 \%$. Findings from this study were very similar to our results: the proportion of "Cluster B" PDs was 66.9\%, whilst "Cluster A" was $16.2 \%$ and "Cluster C" $2.9 \%$.

\section{Personality disorders in relation to violent crimes}

Of those diagnosed with Antisocial, Borderline and Narcissistic disorder in this study, $77.1 \%, 65.3 \%$ and $58.3 \%$, respectively, had been imprisoned for non-violent crimes. Nevertheless, in absolute numbers, most of the violent offenses had been committed by inmates presenting Antisocial Disorder. However, a significant association of violent crimes and "Cluster B" PDs has not been established. According to Palmstierna, Antisocial PD and antisocial personality traits are connected with violence [25]. Similarly Pondé et al. and González et al. suggest a strong association of Antisocial and Borderline PDs with violent crime [26, 27].

High incidence of "Cluster B" PDs is often seen in the literature, although higher rates of "Cluster A" disorders have also been reported in prison's populations, usually associated with a high prevalence of Paranoid PD [9]. In this study, $16.2 \%$ of prisoners had "Cluster A" PDs; $1.9 \%$ Schizotypal; 7.1\% Schizoid, and 7.1\% Paranoid PD. Diagnosis with "Cluster A" disorders had an association with the commitment of violent crimes. Of those diagnosed 
Table 3 Multiple logistic regressions with "violent crimes" and "homicides-attempted homicides" as dependent variables in two Greek prisons $(N=308)$

\begin{tabular}{|c|c|c|}
\hline & OR $(95 \% \mathrm{Cl})$ & $p$ \\
\hline \multicolumn{3}{|l|}{ Violent crimes } \\
\hline \multicolumn{3}{|l|}{ PD Clusters } \\
\hline No PDs & $1.00^{\mathrm{a}}$ & \\
\hline A & $2.86(1.16-7.04)$ & 0.022 \\
\hline B & $1.91(0.85-4.31)$ & 0.118 \\
\hline C & $-{ }^{b}$ & - \\
\hline \multicolumn{3}{|l|}{ PD diagnosis } \\
\hline No PDs & $1.00^{\mathrm{a}}$ & \\
\hline Antisocial & $2.23(0.83-6.05)$ & 0.114 \\
\hline Borderline & $1.91(0.67-5.67)$ & 0.229 \\
\hline Narcissistic & $2.76(0.85-8.97)$ & 0.092 \\
\hline Paranoid & $2.99(0.91-9.81)$ & 0.071 \\
\hline Histrionic & $10.58(0.53-210.99)$ & 0.122 \\
\hline Schizoid & $3.49(1.04-11.73)$ & 0.043 \\
\hline Schizotypal & $10.50(1.53-71.89)$ & 0.017 \\
\hline Passive-aggressive & $2.41(0.51-11.49)$ & 0.268 \\
\hline \multicolumn{3}{|c|}{ Homicides or attempted homicides } \\
\hline \multicolumn{3}{|l|}{ PD Clusters } \\
\hline No PDs & $1.00^{\mathrm{a}}$ & \\
\hline A & $4.25(1.26-14.31)$ & 0.020 \\
\hline B & $1.41(0.42-4.70)$ & 0.574 \\
\hline C & $-{ }^{b}$ & - \\
\hline \multicolumn{3}{|l|}{ PD diagnosis } \\
\hline No PDs & $1.00^{\mathrm{a}}$ & \\
\hline Antisocial & $1.35(0.37-4.90)$ & 0.645 \\
\hline Borderline & $3.34(0.87-12.79)$ & 0.078 \\
\hline Narcissistic & $0.36(0.04-3.50)$ & 0.379 \\
\hline Paranoid & $2.96(0.71-12.26)$ & 0.135 \\
\hline Schizoid & $5.26(1.30-21.23)$ & 0.020 \\
\hline Schizotypal & $8.80(1.23-62.78)$ & 0.030 \\
\hline Passive-aggressive & $2.00(0.30-13.25)$ & 0.474 \\
\hline
\end{tabular}

$O R$ adjusted odds ratio, $C l$ confidence intervals, $P D$ Personal Disorder, Cluster A PD Paranoid/Schizoid/Schizotypal PD, Cluster B PD Antisocial/Borderline/ Histrionic/Narcissistic PD, Cluster C PD Obsessive/Compulsive/Dependent/ Avoidant PD

${ }^{\text {a }}$ Indicates reference category, ${ }^{\text {b }}$ could not be computed due to no distribution

with Schizoid, Schizotypal and Paranoid disorder 50.0\%, $66.7 \%$ and $45.5 \%$, respectively, have been incarcerated for violent crimes. These results are in concordance with Esbec and Echeburúa who reported that increased symptoms of DSM-IV "Cluster A" or "Cluster B" PDs, such as paranoid, narcissistic and antisocial symptoms are significantly associated with violence [28]. Accordingly, Mouilso and Calhoun reported a strong association of Narcissistic PD with sexual assault [29]. On the other hand, increased borderline personality tendencies have been reported in female sexual abusers [30].
Serial offenders as well are more likely to have Narcissistic, Schizoid and/or Obsessive-Compulsive traits. They are also more likely to engage in sexual masochism, partialism, homosexual paedophilia, exhibitionism and/or voyeurism, according to Chan et al. [31]. In addition, Pulay et al. reported an association between Schizoid, Paranoid and Obsessive-Compulsive PDs with violent behavior [32]. Another study by Haller also suggested a significant association of paranoid disturbance with violent crimes [33]. Schizoid PD is related as well with features of psychopathy and Antisocial personality according to Kosson et al. [34]. Loza and Hanna argue that an association exists between Schizoid PD and violent acts [35]. This study found a significant relation only of "Cluster A" disorders with violent offenses.

"Cluster C" disorders accounted for a minority of cases; individuals with Obsessive-Compulsive PD were only $2.3 \%$ of the study sample, whereas Dependent PD and Avoidant PD were few ( 0.3\%). This is in concordance with findings from Finland; "Cluster $C$ " disorders comprised $3.5 \%$ of the entire sample of 593 offenders [19]. However, in contrast with the aforementioned studies, there were no violent crimes committed by offenders with "Cluster C" PD in this study, possibly due to the very small proportion of this PD "Cluster" in the studied population.

As presented in logistic regressions' results (Table 3), prisoners with any type of PD have greater likelihood (OR) of committing a violent crime. Nevertheless, violent crimes were associated significantly $(p \leq 0.05)$ only with Schizotypal and Schizoid PD likely because the comparison group was composed by another type of criminals, instead of being composed by the general population.

\section{Diagnosis with Personality disorders and association with homicides-attempted homicides}

PDs have been found as principal or secondary diagnosis between homicides and attempted homicides offenders [37]. According to Pera and Dailliet, in a sample of 32 Belgian offenders 17 had an Antisocial PD, 8 a Borderline PD, 4 a Paranoid, and 2 a Schizoid PD [38]. Also, in a sample of 36 convicted Jamaican murderers $66 \%$ had an Antisocial PD [39]. Antisocial PD and substance use disorders were the most prevalent psychiatric diagnoses among prisoners that had committed or attempted homicide, as suggested by Kugu et al. [13].

Concerning sexual murderers, they are often diagnosed with a PD, especially with Schizoid PD [40]. Myers and Monaco and others also found an association of Sadistic PD (as described in DSM-IV) with sexual homicide [41, 42]. Concerning serial homicide offenders, they are more likely to have Narcissistic, Schizoid and/or 
Obsessive-Compulsive traits according to Chan et al. [31]. Loza and Hanna reported, as well, an association between Schizoid PD and violent homicidal behavior [35]. Analysis of case reports by Jeffrey Dahmer and Dennis Nilsen underlined an association between schizoid personality traits with violent antisocial behavior [43].

In children, schizotypal features elicit victimization from other children, which in turn predisposes to reactive retaliatory aggression [44]. Lam et al. found that schizotypal personality traits (schizotypy) are associated with antisocial behavior [45]. This relation is replicated in the literature linking Schizotypal Disorder with antisocial behavior and violent crime [45].

Regarding homicide-attempted homicide in this study, the majority was committed by individuals suffering from Antisocial PD. Subjects of "Cluster A" PDs, in total, had committed 17 of the 46 crimes of this type. These results are in contrast to Keue and Borchard [36] and Laajalo et al. [19] studies that found no association between disorders of "Cluster A" and homicides. Prisoners of this study, with disorders of "Cluster A", were 4.25 times more likely to commit murder, while individuals with "Cluster B" disorders were 1.41 times more likely to commit the particular offense, compared with subjects without PD. Specifically for Antisocial PD odds ratio was 1.35, for Borderline PD was 3.34, for Narcissistic PD was 0.36, for Paranoid PD was 2.96, for Schizoid PD was 5.26 and for Schizotypal PD was 8.80 , compared with subjects without PD. However, the committed homicide-attempted homicide was significantly associated with only Schizotypal and Schizoid PD.

Possibly, there is a neurobiological contribution to the association between Schizoid and Schizotypal PD and commitment of homicides or violence crimes. In literature, Schizotypal traits are associated with high hostility levels [46]. According to Raine et al. schizotypy was associated with total and reactive aggression but not with proactive aggression [44]. Sexual murderers are often diagnosed with a Schizoid PD [40]. Lam et al. [45] suggested that orbitofrontal cortex gray matter mediated the effect of schizotypy on antisocial behavior by $53.5 \%$. On the other hand, this association was not significant for prefrontal cortex sub-regions. These findings highlight the specificity of the orbitofrontal cortex in understanding the schizotypy-antisocial behavior relationship. A link between Schizoid PD and Schizotypal PD was suggested by Via et al. [47]. According to them, persons with Schizoid PD-Schizotypal PD have greater bilateral white matter volume in the superior part of the corona radiata, close to motor/premotor regions, compared to healthy controls.

Schug et al. reported that reduced skin conductance orienting to neutral tones may reflect a neurocognitive risk factor, for both Antisocial and Schizotypal PDs that indirectly reflects a common neural substrate to these disorders [48]. Other researchers reported that individuals with Schizotypal PD display heightened activation in the neural circuitry, involved in reward and decision making when viewing biological motion stimuli in addition to a positive correlation between increased blood oxygenation level-dependent, signal responses related to biological motions and clinical symptoms [49]. These findings suggest that enhanced responses arise within the reward network for individuals with Schizotypal PD and are possibly related to the "peculiar" ways that individuals with Schizotypal disorder behave in social contexts. It might be the "unemotional and cold part" of individuals with Schizoid and Schizotypal PD that contributes to the increased occurrence of "lethal violence".

This study addresses certain limitations. Although the number of the participants is quite large, a bigger sample of individuals would have enhanced our results. For example, association of Paranoid ("Cluster A") and Narcissistic ("Cluster B") PDs with violent crimes was slightly not statistically significant ( $p$ values were 0.09 and 0.07 , respectively). Another limitation is that issues of "free" psychopathology and counter-transference were not addressed in the initial protocol. It is also likely that Personality disorders have been overestimated in this study as well as in studies using structured diagnostic instruments. Much higher prevalence possibly has been reported compared to clinically based studies.

\section{Conclusions}

Most of the Greek prison inmates were diagnosed with a PD with a clear predominance of Antisocial PD. Nevertheless, significant associations of violent crimes and the offense of homicides-attempted homicides were found for the Schizoid and Schizotypal PD. No association of "Cluster B" or "Cluster C" PDs with violent crimes was elicited. This study-conducted for the first time in a Greek prisoners' population-provides evidence that murders and attempted murders are strongly associated with Schizoid and Schizotypal PDs. Further research is necessary to study in more depth the possible association of PDs-especially of the "Cluster A"-and the type of crime in Greece. Also, studies with larger samples and higher statistical power could investigate the role of other social, economic, demographic and clinical determinants in appearance of violent crimes and committed or attempted homicides.

\section{Abbreviations}

PDs: Personality disorders; MINI: Mini International Neuropsychiatric Interview: PDQ-4: Personality Diagnostic Questionnaire-4; M: mean; N: absolute frequencies; SD: standard deviation; OR: odds ratios; Cl: confidence intervals. 


\section{Authors' contributions}

$A A, A D$ and $V M$ contributed to conception and design and acquisition of data; $A A, V M$ and $I Z$ to analysis and interpretation of data; AA, IM, IZ, GT, VM and AD have been involved in drafting and revising the manuscript; $A A, E R, C P$ and AD have given final approval of the version to be published. Each author has participated sufficiently and agreed that questions related to the accuracy and integrity of the work are appropriately investigated and resolved. All authors read and approved the final manuscript.

\section{Author details}

1 2nd Psychiatric Department of the University of Athens, Attikon Hospital, Athens, Greece. ${ }^{2}$ 1st Psychiatric Department of the University of Athens, Aeginition Hospital, Athens, Greece. ${ }^{3}$ Organization Against Drugs, Athens, Greece.

\section{Acknowledgements}

Not applicable.

\section{Competing interests}

The authors declare that they have no competing interests.

\section{Availability of data and materials}

The datasets generated and analyzed during the current study are not publicly available because the building of a public database was out of the aim and the resources of this study; but the datasets are available from the corresponding author on reasonable request.

\section{Consent for publication}

Not applicable.

\section{Ethics approval and consent to participate}

The study was conducted, in compliance with the applied rules of medical ethics. The study was evaluated and approved by the Ethics Committee of the Attikon University Hospital (Decision 3/5-3-12). All individuals gave informed consent to participate.

\section{Funding}

The authors declare that no sponsor played a role in funding the design, collection, and analysis, interpretation of data or in writing the manuscript.

\section{Publisher's Note}

Springer Nature remains neutral with regard to jurisdictional claims in published maps and institutional affiliations.

Received: 7 May 2018 Accepted: 31 July 2018

Published online: 10 August 2018

\section{References}

1. American Psychiatric Association. Diagnostic and statistical manual of mental disorders, DSM-IV. Washington: American Psychiatric Press Inc; 1994.

2. Yu R, Geddes JR, Fazel S. Personality Disorders, violence, and antisocial behavior: a systematic review and meta-regression analysis. J Pers Disord. 2012;26(5):775-92.

3. Douzenis A, Tsopelas C, Tzeferakos G. Medical comorbidity of cluster B Personality Disorders. Curr Opin Psychiatry. 2012;25(5):398-404.

4. Alevizopoulos $\mathrm{G}$, Igoumenou A. Psychiatric disorders and criminal history in male prisoners in Greece. Int J Law Psychiatry. 2016;47:171-5.

5. Coid JW. Personality Disorders in prisoners and their motivation for dangerous and disruptive behavior. Crim Behav Ment Health. 2002;12(3):209-26.

6. Black DW, Gunter T, Allen J, Blum N, Arndt S, Wenman G, Sieleni B. Borderline personality disorder in male and female offenders newly committed to prison. Compr Psychiatry. 2007:48(5):400-5.

7. Fazel S, Danesh J. Serious mental disorder in 23000 prisoners: a systematic review of 62 surveys. Lancet. 2002;359(9306):545-50.

8. Richard-Devantoy S, Olie JP, Gourevitch R. Risk of homicide and major mental disorders: a critical review. Encephale. 2009;35(6):521-30.
9. Riesco Y, Pérez Urdániz A, Rubio V, Izquierdo JA, Sánchez Iglesias S, Santos JM, Carrasco JL. The evaluation of Personality Disorders among inmates by IPDE and MMPI. Actas Luso Esp Neurol Psiquiatr Cienc Afines. 1998;26(3):151-4.

10. Piselli M, Attademo L, Garinella R, Rella A, Antinarelli S, Tamantini A, Quartesan R, Stracci F, Abram KM. Psychiatric needs of male prison inmates in Italy. Int J Law Psychiatry. 2015;41:82-8.

11. Coolidge FL, Segal DL, Klebe KJ, Cahill BS, Whitcomb JM. Psychometric properties of the Coolidge Correctional Inventory in a sample of 3,962 prison inmates. Behav Sci Law. 2009;27(5):713-26.

12. Köhler D, Heinzen $H$, Hinrichs $G$, Huchzermeier $C$. The prevalence of mental disorders in a German sample of male incarcerated juvenile offenders. Int J Offender Ther Comp Criminol. 2009;53(2):211-27.

13. Kugu N, Akyuz G, Dogan O. Psychiatric morbidity in murder and attempted murder crime convicts: a Turkey study. Forensic Sci Int. 2008;175(2-3):107-12.

14. Naidoo S, Mkize DL. Prevalence of mental disorders in a prison population in Durban, South Africa. Afr J Psychiatry. 2012;15(1):30-5.

15. Longato-Stadler E, von Knorring L, Hallman J. Mental and Personality Disorders as well as personality traits in a Swedish male criminal population. Nord J Psychiatry. 2002;56(2):137-44.

16. Fotiadou M, Livaditis M, Manou I, Kaniotou E, Xenitidis K. Prevalence of mental disorders and deliberate self-harm in Greek male prisoners. Int J Law Psychiatry. 2006;29(1):68-73.

17. Fountoulakis KN, Leucht S, Kaprinis GS. Personality Disorders and violence. Curr Opin Psychiatry. 2008;21(1):84-92.

18. Crump C, Sundquist K, Winkleby MA, Sundquist J. Mental disorders and vulnerability to homicidal death: Swedish nationwide cohort study. BMJ. 2013:346:f557.

19. Laajalo T, Ylipekka M, Häkkänen-Nyholm H. Homicidal behavior among people with avoidant, dependent and obsessive-compulsive (cluster C) personality disorder. Crim Behav Ment Health. 2013;23(1):18-29.

20. Papadimitriou GN, Berati S, Matsoukas TH, Soldatos KR. Mini International Neuropsychiatric Interview, Greek Version 5.0.0. DSM-IV, 2005.

21. Black DW, Arndt S, Hale N, Rogerson R. Use of the Mini International Neuropsychiatric Interview (MINI) as a screening tool in prisons: results of a preliminary study. J Am Acad Psychiatry Law. 2004;32(2):158-62.

22. Tasoulas S, Siousioura D. Personality Diagnostic Questionnaire (PDQ-4) in the Greek Language. Tetr Psychiatr. 2005;92:87-96.

23. Abdin E, Koh KG, Subramaniam M, Guo ME, Leo T, Teo C, Tan EE, Chong SA. Validity of the Personality Diagnostic Questionnaire-4 (PDQ$4+)$ among mentally ill prison inmates in Singapore. J Pers Disord. 2011;25(6):834-41.

24. Lanqeveld $\mathrm{H}$, Mehlus $\mathrm{H}$. Are psychiatric disorders identified and treated by in-prison health services? Tidss Nor Laeqeforen. 2004;124(16):2094-7.

25. Palmstierna T. Personality disorders, violence and criminal behavior. Lakartidningen. 2016;113:1-3

26. Pondé MP, Caron J, Mendonca MS, Freire AC, Moraeu N. The relationship between mental disorders and types of crime in inmates in Brazilian prison. J Forensic Sci. 2014;59(5):1307-14.

27. González RA, Igoumenou A, Kallis C, Coid JW. Borderline personality disorder and violence in the UK population: categorical and dimensional trait assessment. BMC Psychiatry. 2016:16:180.

28. Esbec E, Echeburúa E. Violence and Personality Disorders: clinical and forensic implications. Actas Esp Psiquiatr. 2010;38(5):249-61.

29. Mouilso ER, Calhoun KS. Personality and perpetration: narcissism among college sexual assault perpetrators. Violence Against Women 2016:22(10):1228-42.

30. Tsopelas C, Tsetsou S, Ntounas P, Douzenis A. Female perpetrators of sexual abuse of minors: what are the consequences for the victims? Int J Law Psychiatry. 2012;35(4):305-10.

31. Chan HC, Beauregard E, Myers WC. Single-victim and serial sexual homicide offenders: differences in crime, paraphilias and personality traits. Crim Behav Ment Health. 2015;25(1):66-78.

32. Pulay AJ, Dawson DA, Hasin DS, Goldstein RB, Ruan WJ, Pickering RP, Huang B, Chou SP, Grant BF. Violent behavior and DSM-IV psychiatric disorders: results from the national epidemiologic survey on alcohol and related conditions. J Clin Psychiatry. 2008;69(1):12-22.

33. Haller R. What makes a mental ill violent? Psychiatr Danub. 2005;17(3-4):143-53. 
34. Kosson DS, Blackburn R, Byrnes KA, Park S, Logan C, Donnelly JP. Assessing interpersonal aspects of schizoid Personality Disorder: preliminary validation studies. J Pers Assess. 2008;90(2):185-96.

35. Loza W, Hanna S. Is schizoid personality a forerunner of homicidal or suicidal behavior?: a case study. Int J Offender Ther Comp Criminol. 2006;50(3):338-43.

36. Keue A, Borchard B, Hoyer J. Mental disorders in a forensic sample of sexual offenders. Eur Psychiatry. 2004;19(3):123-30.

37. Fazel S, Grann M. Psychiatric morbidity among homicide offenders: a Swedish population study. Am J Psychiatry. 2004;161(11):2129-31.

38. Pera SB, Dailliet A. Homicide by mentally ill: clinical and criminological analysis. Encephale. 2005;31(5Pt1):539-49.

39. Hickling FW, Walcott G. Personality Disorder in convicted Jamaican murderers. West Indian Med J. 2013;62(5):453-7.

40. Koch J, Berner W, Hill A, Briken P. Sociodemographic and diagnostic characteristics of homicidal and nonhomicidal sexual offenders. J Forensic Sci. 2011;56(6):1626-31.

41. Myers WC, Monaco L. Anger experience, styles of anger expression, sadistic personality disorder, and psychopathy in juvenile sexual homicide offenders. J Forensic Sci. 2000:45(3):698-701.

42. Leach $G$, Meloy JR. Serial murder of six victims by an African-American male. J Forensic Sci. 1999;44(5):1073-8.
43. Martens WH, Palermo GB. Loneliness and associated violent antisocial behavior: analysis of the case reports of Jeffrey Dahmer and Dennis Nilsen. Int J Offender Ther Comp Criminol. 2005;49(3):298-307.

44. Raine A, Fung AL, Lam BY. Peer victimization partially mediates the schizotypy-aggression relationship in children and adolescents. Schizophr Bull. 2011;37(5):937-45.

45. Lam BY, Yang Y, Raine A, Lee TM. Neural mediator of the schizotypy-antisocial behavior relationship. Transl Psychiatry. 2015;5:e669.

46. Schaub M, Boesch L, Stohler R. Association between aggressiveness, schizotypal personality traits and cannabis use in Swiss psychology students. Psychiatry Res. 2006;143:299-301.

47. Via E, Orfila C, Pedreño C, Rovira A, Menchón JM, Cardoner N, Palao DJ, Soriano-Mas C, Obiols JE. Structural alterations of the pyramidal pathway in schizoid and schizotypal cluster A Personality Disorders. Int J Psychophysiol. 2016;110:163-70.

48. Schug RA, Raine A, Wilcox RR. Psychophysiological and behavioral characteristics of individuals comorbid for antisocial personality disorder and schizophrenia-spectrum personality disorder. Br J Psychiatry. 2007;191:408-14

49. Hur JW, Blake R, Cho Kl, Kim J, Kim SY, Choi SH, Kang DH, Kwon JS. Biological motion perception, brain responses, and schizotypal personality disorder. JAMA Psychiatry. 2016;73(3):260-7.
Ready to submit your research? Choose BMC and benefit from:

- fast, convenient online submission

- thorough peer review by experienced researchers in your field

- rapid publication on acceptance

- support for research data, including large and complex data types

- gold Open Access which fosters wider collaboration and increased citations

- maximum visibility for your research: over 100M website views per year

At BMC, research is always in progress.

Learn more biomedcentral.com/submissions 